\title{
Immobilized $\beta$-Cyclodextrin Catalyst for Selective Synthesis of 4-Hydroxybenzoic Acid
}

\author{
Makoto KomiYama, ${ }^{*}$ Izuru SugIURA, and Hidefumi HiraI \\ Department of Industrial Chemistry, Faculty of Engineering, The University of Tokyo, \\ Hongo, Bunkyo-ku, Tokyo 113, Japan
}

(Received April 18, 1985)

\begin{abstract}
KEY WORDS Cyclodextrin / Selective Synthesis / Immobilization / 4-Hydroxybenzoic Acid /
\end{abstract}

Cyclodextrins, cyclic oligomers of glucose molecules, ${ }^{1,2}$ were used in the selective syntheses of some chemicals. ${ }^{3-13}$ The selective catalyses involve regioselectivity, regulation of molecular size of intermediates and products, and/or protection of unstable products.

Previously, ${ }^{10,13}$ selective synthesis of 4 -hydroxybenzoic acid from phenol and carbon tetrachloride was carried out using $\beta$-cyclodextrin as catalyst. Formation of 2-hydroxybenzoic acid was largely inhibited by $\beta$-cyclodextrin, resulting in $99 \%$ selectivity for 4-hydroxybenzoic acid.

This paper reports that the $\beta$-cyclodextrin immobilized by epichlorohydrin is a still better catalyst for the selective synthesis of 4-hydroxybenzoic acid. A selectivity as high as $100 \%$ is achieved with this immobilized catalyst. Furthermore, separation of the catalyst from the reaction mixture and reusage of the recovered catalyst are described.

\section{EXPERIMENTAL}

An immobilized $\beta$-cyclodextrin catalyst was prepared by the reaction of $50.0 \mathrm{~g}(44.1 \mathrm{mmol})$ of $\beta$-cyclodextrin and $34.5 \mathrm{ml}(441 \mathrm{mmol})$ of epichlorohydrin at $50^{\circ} \mathrm{C}$ for $40 \mathrm{~min}$ in $80 \mathrm{ml}$ of $50 \mathrm{wt} \%$ aqueous sodium hydroxide solution containing $50 \mathrm{mg}(1.3 \mathrm{mmol})$ of sodium tetra- hydroborate. The resulting solid was sufficiently washed with acetone and with water, and then was dried in vacuo at $60^{\circ} \mathrm{C}$ for $12 \mathrm{~h}$. The catalyst was obtained in a form of beads of diameter $1-3 \mathrm{~mm}$. The molar ratio of $\beta$ cyclodextrin and 2-hydroxypropenyl residue, derived from epichlorohydrin, was $1.0: 3.3$, as determined by elemental analysis. Obsd: C, $47.00 \%$; H, $6.60 \%$. Calcd: C, $46.80 \%$; H, $6.72 \%$.

In the selective synthesis of 4-hydroxybenzoic acid, phenol $(1.5 \mathrm{~g}, 15.9 \mathrm{mmol})$, copper metallic powder $(0.2 \mathrm{~g}, 3.1 \mathrm{mmol})$, and the immobilized $\beta$-cyclodextrin catalyst $(1.5 \mathrm{~g}, 1.1$ milliequivalent of $\beta$-cyclodextrin residue) were charged to $20 \mathrm{ml}$ of $20 \mathrm{wt} \%$ aqueous sodium hydroxide solution. Then carbon tetrachloride $(3.0 \mathrm{ml}, 31.1 \mathrm{mmol})$ was added. The reaction was carried out at $80^{\circ} \mathrm{C}$ for $15 \mathrm{~h}$ under nitrogen with vigorous stirring.

After the reaction, the reaction mixture was centrifugated at $3000 \mathrm{rpm}$ for $10 \mathrm{~min}$. The liquid layer was sufficiently extracted with diethyl ether after being acidified with hydrochloric acid, and the ether layer was evaporated. The product analysis was made with the use of HPLC (Toyo Soda Co., LS410K, $\mathrm{MeOH}-100$ column, $30 \mathrm{~cm}, 25^{\circ} \mathrm{C}$, eluent: $6: 4$ water-ethanol).

The solid obtained by centrifugation was 
further used as the catalyst in the following run.

\section{RESULTS AND DISCUSSION}

As shown in Table I, 4-hydroxybenzoic acid is synthesized at $100 \%$ selectivity and in $89 \mathrm{~mol} \%$ yield in the presence of the immobilized $\beta$-cyclodextrin catalyst. In its absence, however, the selectivity is $56 \%$ and the yield is only $15 \mathrm{~mol} \%$.

The immobilized catalyst was easily recovered from the reaction mixture by centrifugation, as a solid containing copper powder. In the following runs, where only phenol and carbon tetrachloride were additionally charged to the recovered solid in $20 \mathrm{wt} \%$ aqueous sodium hydroxide solution, the selectivity for 4-hydroxybenzoic acid was $100 \%$ and the yield was satisfactorily high, as also shown in Table I. Furthermore, $100 \%$ selectivity and yields larger than $90 \mathrm{~mol} \%$ were attained in the following three runs. Thus, no decrease in the catalytic activity was detected up to six (the maximum number examined) repeated usage of the catalyst.

The repeated use of free $\beta$-cyclodextrin, which was not immobilized, was also examined. After the reaction under identical conditions for the reaction with the immobilized catalyst, the reaction mixture was acidified with hydrochloric acid, followed by centrifugation. The recovered $\beta$-cyclodextrin was used for the following runs. In the successive three runs, the selectivity for 4-hydroxybenzoic acid was $100 \%$. In the fourth, the fifth, and the sixth runs, however, the selectivity decreased to $85 \%, 76 \%$, and $60 \%$, respectively. The decrease in the selectivity with increasing number of repeated runs is attributable to loss of $\beta$ cyclodextrin during the recovery of the catalyst after each of runs.

The selective synthesis using the immobilized $\beta$-cyclodextrin catalyst probably proceeds in a similar manner as shown for the selective synthesis using free $\beta$-cyclodextrin. ${ }^{13}$ $\beta$-Cyclodextrin regulates the mutual conformation between phenol and trichloromethyl cation, produced in situ from carbon tetrachloride with the catalysis of copper powder, through non-covalent interactions with each of them. The para-carbon atom of phenol is selectively attacked by the cation, since it is located near the cation due to the regulation.

Quite a high selectivity exhibited by the immobilized $\beta$-cyclodextrin catalyst is associated with the negatively charged reaction field produced by alkoxide ions of the $\beta$ cyclodextrin residues. The $\mathrm{p} K_{\mathrm{a}}$ of the secondary hydroxyl groups of $\beta$-cyclodextrin is

Table I. Selective synthesis of 4-hydroxybenzoic acid using the immobilized $\beta$-cyclodextrin catalyst

\begin{tabular}{|c|c|c|c|c|}
\hline \multirow{3}{*}{$\begin{array}{l}\text { Immobilized } \\
\beta \text {-cyclodextrin } \\
\text { catalyst }\end{array}$} & \multirow{3}{*}{$\begin{array}{c}\text { Number of } \\
\text { repeated } \\
\text { usage }\end{array}$} & \multicolumn{2}{|c|}{ Carboxylation yield } & \multirow{3}{*}{ Selectivity $^{\mathrm{c}}$} \\
\hline & & \multicolumn{2}{|c|}{$\mathrm{mol} \%$} & \\
\hline & & para $^{\mathbf{a}}$ & ortho $^{\mathrm{b}}$ & \\
\hline \multirow[t]{3}{*}{ Presence } & 1 & 89 & 0 & 100 \\
\hline & $2^{\mathrm{d}}$ & 91 & 0 & 100 \\
\hline & $3^{d}$ & 93 & 0 & 100 \\
\hline Absence & - & 15 & 12 & 56 \\
\hline
\end{tabular}

a Yield for 4-hydroxybenzoic acid with respect to the charged phenol.

b Yield for 2-hydroxybenzoic acid with respect to the charged phenol.

c Selectivity for 4-hydroxybenzoic acid.

d Catalysis by the immobilized catalyst, recovered by centrifugation from the reaction mixture. 
around $12 .{ }^{1}$ This reaction field effectively traps trichloromethyl cations, and thus the selective reactions involving the catalysis of the $\beta$ cyclodextrin residues is still more predominant to the nonselective reactions without the catalysis of the $\beta$-cyclodextrin residues.

In summary, selective synthesis of 4-hydroxybenzoic acid is successfully achieved using the $\beta$-cyclodextrin immobilized by epichlorohydrin. The catalyst is easily recovered from the reaction mixture and can be repeatedly used without apparent decrease in the activity.

\section{REFERENCES}

1. M. L. Bender and M. Komiyama, "Cyclodextrin Chemistry," Springer-Verlag, Berlin, 1978.

2. J. Szejtli, "Cyclodextrins and their Inclusion
Complexes," Akadémiai Kiadó, Budapest, 1982.

3. R. Breslow and P. Campbell, J. Am. Chem. Soc., 91, 3085 (1969).

4. R. Breslow and P. Campbell, Bioorg. Chem., 1, 140 (1971).

5. R. Breslow, H. Kohn, and B. Siegel, Tetrahedron Lett., 1645 (1976).

6. I. Tabushi, K. Fujita, and H. Kawakubo, J. Am. Chem. Soc., 99, 6456 (1977).

7. I. Tabushi, K. Yamamura, K. Fujita, and H. Kawakubo, J. Am. Chem. Soc., 101, 1019 (1979).

8. M. Ohara and J. Fukuda, Pharmazie, 33, H7 (1978).

9. M. Komiyama and H. Hirai, Makromol. Chem., Rapid Commun., 2, 177, 601, 707, 715, 733, 757, 759 (1981).

10. M. Komiyama and H. Hirai, Makromol. Chem., Rapid Commun., 2, 661 (1981).

11. M. Komiyama and H. Hirai, Bull. Chem. Soc. Jpn., 54, 2053 (1981).

12. M. Komiyama and H. Hirai, J. Am. Chem. Soc., 105, 2018 (1983).

13. M. Komiyama and H. Hirai, J. Am. Chem. Soc., 106, 174 (1984). 